\title{
WHY DOES HEADQUARTERS VOLUNTARILY TRANSFER ITS BARGAINING POWER TO BUSINESS UNITS?
}

\author{
Shin'ya Okuda ${ }^{* *}$, Takaya Kubota ${ }^{2}$ and Yoshimi Chujo ${ }^{3}$ \\ ${ }^{1 *}$ Graduate School of Economics, Nagoya City University, Japan \\ E-mail: s-okuda@econ.nagoya-cu.ac.jp \\ ${ }^{2}$ Graduate School of Economics, Nagoya University, Japan \\ E-mail: kubota.takaya@h.mbox.nagoya-u.ac.jp \\ ${ }^{3}$ Faculty of Management Information, Hannan University, Japan \\ E-mail: chujo@hannan-u.ac.jp
}

\begin{abstract}
The objective of our paper is to provide the reason why headquarters voluntarily transfer its bargaining power to the business unit by stylizing an incomplete contract model. Our model shows that the equilibrium bargaining power selected by the headquarters is negatively correlated with the importance attached to the business unit's operations. It means that when incomplete contracts severely restrict an important business unit's incentive to invest because of holdup problem, the headquarters should necessarily provide the business unit with some degree of bargaining power. This result is consistent with the fact that the independence of a business unit (e.g., spin-offs) is a commonly observable practice. Building on our model, independence of the business unit can be interpreted as a consequence of a gradual delegation of authority by the headquarters. Our paper contributes to both of economics and management accounting literature by providing a model concerning to a decision of organizational structure.
\end{abstract}

Keywords: bargaining power; cost structure; independence of business unit

\section{ARTICLE INFO}

\section{Article History:}

Received: 20 February 2019

Accepted: 15 July 2019

Published: 31 August 2019 


\section{INTRODUCTION}

A business unit, which is one fragment of a company, is commonly observed to grow into a specific operating division or even a wholly owned subsidiary, finally becoming an independent company. We examine explanations of why a business unit gradually acquires more independence from its parent company. Several classical studies regarding the boundaries of firms constitute the "transaction cost theory" (e.g., Coase, 1937; Williamson, 1985). The transaction cost theory argues that the boundary of the firm is designed to minimize transaction costs. Other studies such as Grossman and Hart (1986) and Hart and Moore (1990) approach the boundary aspect from the context of incomplete contracts. They suggest that the boundary of a firm is set by preliminarily considering how to appropriately allocate the residual control in order to resolve the prevalent holdup problem. These studies consider the distribution problem inside a company given that bargaining power is exogenously endowed to constituents of the company.

Our study extends previous research and focuses on the phenomenon that the company headquarters voluntarily reduces its own bargaining power. We investigate the theoretical background as to why the company headquarters, albeit entitled with significant bargaining power, accepts the reduction in the share of total profit. In doing so, we seek the optimal bargaining power that is relinquished from the headquarters to the business unit. This approach has not been adopted by prior studies.

We present a stylized model in which the headquarters can acquire more profit by transferring some portion of its bargaining power to the important business unit, which generates greater added value in its value chain. The result is not contradictory because, as the role played by the business unit becomes more important, it is increasingly beneficial to provide the business unit with an incentive to invest more in its own operations. As long as additional profit generated from marginal investments by the business unit compensates for the loss incurred by the headquarters by losing a fraction of its bargaining power, the headquarters will readily choose to cede its bargaining power.

The remainder of this article is structured as follows. Section 2 discusses prior research. Section 3 develops a simple model to depict the 
bargaining game and the propositions drawn from the model and compares these with the pure Nash bargaining solution. Section 4 shows numerical examples by altering the level of the production cost parameter. Section 5 includes discussion about the results of our analysis. Finally, Section 6 concludes.

\section{LITERATURE REVIEW}

Some studies do not determine the bargaining power per se but rather consider the distribution problem inside a company given the bargaining power exogenously endowed to constituents of the company (e.g., manager and employees). Aoki (1988) formulates the distribution of payoffs between these constituents by solving the Nash product maximization and concludes that bargaining leads to the appropriate distributive share assigned to each player. In accordance with Aoki's (1988) model, Sasaki, Yonezawa, and Azeez (2008) empirically demonstrate that the conflicts of interest and the distribution problem between a manager and employees result in a significant deterioration of shareholder value. In a context of a principalagent relationship facing adverse selection, Inderst (2002) proposes a model in which the principal can reduce information rent, thereby removing distortion of the contract by ceding bargaining power to the agent, while bargaining power is not the variable of direct interest but an exogenously given condition. In contrast, our study contributes to the literature by considering the setting where players decide the level of their bargaining power in the profit maximization process.

However, several studies focus on bargaining power determined strategically and endogenously. Ishida and Matsushima (2009) analyze the manner with which the labor union decides its rent-seeking activity level to enhance its bargaining power against the company. Similarly, Levy (1998) addresses union dues as an endogenous variable, while the level of union dues exhibits tradeoffs between the strength of union members' connection and the rate of participation in the union. Guo et al. (2018) argue that in a supply chain, suppliers that dominate the game hold all the bargaining power. In contrast, when retailers are the decision-makers, they attempt to retain the bargaining power level, which allows the suppliers to participate in the contract. We employ a different approach to this bargaining game 
by focusing on why the downstream player (i.e., headquarters) abandons some of its bargaining power to the upstream player (i.e., business unit).

In addition, empirical scholars have attempted to clarify the antecedents of spin-offs. Iturriaga and Cruz (2008) used 166 spin-off cases of Spanish companies and identified three reasons. Panela et al. (2019) examined accounting and financial antecedents of spin-offs in the lodging industry. They found that six accounting and financial factors influence company's decision of spin-offs. The central findings drawn from our theoretical model have implications for this line of empirical research as well.

\section{MODEL DEVELOPMENT}

We consider a perfectly competitive market with two risk-neutral playersheadquarters and business unit — denoted by $H$ and $U$, respectively. Before production, $U$ decides to produce $x$ units of goods, and $H$ must purchase all of the goods provided by $U$. To simplify, let the sales price be fixed at unity. Such a market price enables $H$ to sell all the goods to consumers. Because $H$ cannot control all the manufacturing processes of $U$ due to its inherent assets, including human resources, it is necessary for $H$ to delegate to $U$ the decision rights regarding manufacturing capacity.

We further assume that $H$ can determine the bargaining power allocation after observing the cost structure of $U$ so that $H$ can achieve the maximum profit. This assumption is consistent with the case of spinoffs where $H$ is supposed to abandon some of its bargaining power as the size of production grows. ${ }^{1}$ In this article, we define bargaining power as $H$ 's contractible share of $U$ 's revenue that will be realized from the sale of goods. When the size of $U$ is relatively small, $H$ generally possesses a large fraction of the revenue. In this case, $U$ has little incentive to invest. However, once $U$ becomes an operating division, $H$ may allow $U$ to invest some fraction of sales revenue in its own business or to increase the wage of employees involved in the division. This possibility implies a somewhat decreased bargaining power of $H$. Moreover, when $U$ grows into a subsidiary,

1 For example, regarding the extended bargaining power by $H$, consider the case in which a new drug or internet venture becomes an affiliate of an extant major company. The fact that $U$ voluntarily abandons its bargaining power is similar to our assumption that $H$ can determine the bargaining power ex post. 
$H$ 's access to $U$ 's revenue is restricted to only a formal distribution of the outcome proportionate to its equity share. Our model explores the bargaining game between $H$ and $U$, which explicitly considers the condition where $H$ cedes bargaining power to maximize profit.

The game is assumed to have the following timeline. (1) The cost structure of $U$ is determined, which is characterized by a nonnegative marginal cost parameter $\beta$. This parameter is known to both players. (2) $H$ chooses the optimal bargaining power level $t$, where $0 \leq t \leq 1$. (3) $U$ then selects the production volume $x \geq 0$, given the bargaining power $t$ and the cost structure $\beta$. After $x$ units are produced and sold, profits of $H$ and $U$ are realized. The profits of $H$ and $U$, denoted $\pi H$ and $\pi U$, respectively, are therefore obtained as follows:

$$
\begin{aligned}
& \pi_{\mathrm{H}}(t, \beta, x)=t\left\{(1+\beta) x-x^{2}\right\} \\
& \text { and } \\
& \pi_{\mathrm{U}}(t, \beta, x)=(1-\mathrm{t})\left\{(1+\beta) x-x^{2}\right\}-\beta x
\end{aligned}
$$

The terms inside the curly brackets denote the total revenue from production that is allocated according to each player's bargaining power $t$. Because we consider a perfectly competitive market, the terms inside the curly brackets is concave and increasing in $x$. This setting about revenue is same as Guo et al. (2018) assumed. Equation (2) indicates that $U$ is a residual claimant and solely responsible for the irreversible investment (i.e., $\beta x$ ). Accordingly, an increase in such investment $\beta x$, which in turn affects the profit of $H$, can be interpreted as the incremental importance attributed to $U$ 's project.

First, we consider the optimal production volume $x$ if the company attempts to maximize total profit, which means that $U$ has no bargaining power. In this case, the company selects the production volume to maximize profit, as follows:

$$
\pi(\mathrm{t}=1, \beta, x)=\pi_{\mathrm{H}}(\mathrm{t}=1, \beta, x)+\pi_{\mathrm{U}}(\mathrm{t}=1, \beta, x)=x-x^{2}
$$


It is easily shown that, and it does not depend on the marginal cost $\beta$. Note that equation (3) is identical to the total profit when any decision concerning production level is completely under the control of $H$ (i.e., $t=1$ ).

Next, we address the case of incomplete contracts, in which we assume that the production volume choice is wholly dependent on $U$. Given the known marginal cost $\beta$ and selected bargaining power $t$, the first-order condition in equation (2) yields $U$ 's optimal production level as a function of these parameters:

$$
x^{*}=\frac{1-t(1+\beta)}{2(1-t)}
$$

Applying backward induction, $H$ anticipates the response of $U$ expressed in equation (4) and chooses the optimal bargaining power. The profit of $H$ is therefore reformulated in terms of this response, as follows:

$$
\begin{gathered}
\pi_{H}\left(t, \beta, x^{*}(t, \beta)\right)=t\left\{(1+\beta) x^{*}(t, \beta)-\left(x^{*}(t, \beta)\right)^{2}\right\} \\
=t\left\{(1+\beta) \frac{(1-t(1+\beta))}{2(1-t)}-\left(\frac{(1-t(1+\beta))}{2(1-t)}\right)^{2}\right\}
\end{gathered}
$$

Taking the derivative of equation (5) with respect to $t$, we obtain the first-order condition as follows:

$$
1-2 \beta+\frac{t \beta^{2}((3-t) t-4)}{(1-t)^{3}}=0
$$

Implicitly differentiating equation (6) and solving for $d t / d \beta$ yields

$$
\frac{d t}{d \beta}=-\frac{(2+t) \beta^{3}}{(1-t)^{4}(1+\beta)}<0
$$

Parametric restrictions prescribed above warrant the strict inequality expressed by equation (7). To summarize: 
PROPOSITION: Given the cost structure $0<\beta$, the bargaining power choice by headquarters H responds negatively to the importance of business unit $U$ represented by $\beta$.

The intuition behind this proposition is that as the importance of the operations conducted by $U$ rises, $H$ gradually cedes its bargaining power to motivate $U$ to invest. By obtaining the bargaining power, $U$ not only increases its investment but also attains a larger profit $\pi U$. Importantly, a larger $\pi U$ in turn increases the transfer of revenue to $H$ and makes the total profit of the company $\pi$ higher than that achieved when there is no bargaining game. Consequently, $H$ is sufficiently compensated for the loss incurred by abandoning its bargaining power.

Next, following the research on incomplete contracts, we examine the case in which the outcome of $U$ 's operation is distributed based on the Nash bargaining solution. Assuming that $U$ 's outcome is distributed corresponding to equivalent bargaining powers (i.e., $t=1 / 2$ ), we can rewrite $U$ 's profit as follows:

$$
\pi_{U}(\beta, x)=\frac{1}{2}\left\{(1+\beta) x-x^{2}\right\}-\beta x,
$$

and, taking the derivative with respect to $x$, we obtain

$$
x^{* *}=\frac{1-\beta}{2}
$$

Clearly, the optimal production volume of $U$ is strictly decreasing in $\beta .{ }^{2}$ However, we emphasize that this result is not sufficient because the perspective employed here disregards the power balance between players. Once we consider this, the increase in $\beta$ does not decrease production because the corresponding reduction in $t$ provides $U$ with greater incentive to invest in its current operations.

2 In this case, the level of $\beta$ must be smaller than one for the production volume to remain positive. On the other hand, in the model we provided first, $\beta$ can take any nonnegative value. 


\section{NUMERICAL EXAMPLE}

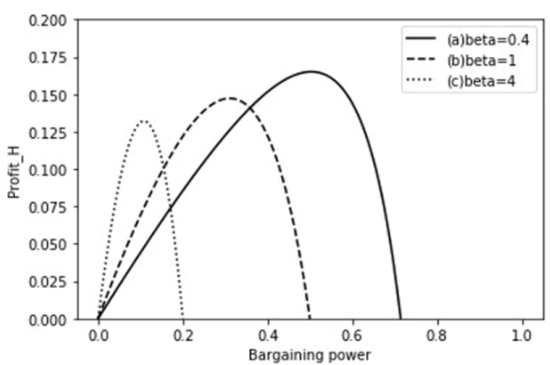

Figure 1: Relationship between $\pi H$ and $t$ for a given $\beta$

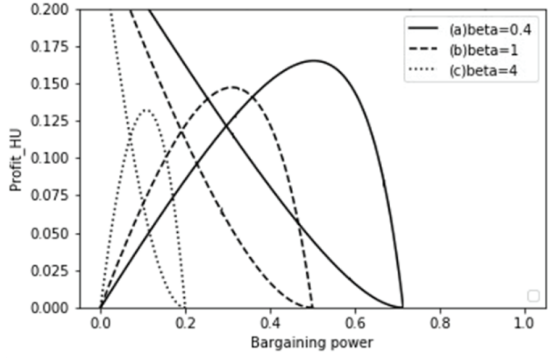

Figure 2: Relationship between $\pi H$ and $\pi \mathrm{U}$

We provide a numerical example to better understand the relationship between $\pi H$ and parameters $t$ and $\beta$. Figure 1 illustrates the case of $\beta$ taking values of (a) 0.4 , (b) 1 , and (c) 4 . Compared with the case of (a), $H$ facing a higher $\beta$ (i.e., (b) and (c)) realizes greater profits by ceding bargaining power due to the increased revenue, effectively recovering the loss from diluted bargaining power. In short, as confirmed in the previous section, the greater the importance of $U$ 's business, the larger portion of bargaining power would be willingly abandoned by $H$.

We gain additional insight from Figure 2. Three convex graphs describe $U$ 's profit at each $\beta$. Observe that is strictly positive at $H$ 's optimal points. In other words, as a result of $H$ 's profit maximization, $U$ also gains profit.

\section{DISCUSSION}

This paper contributes to the literature because it explicitly addresses the optimal share of bargaining power between players by recognizing endogenous choice of it. In doing so, we explain the theoretical reason why a business unit gradually grow into an independent company. In addition to this, because the degree of a business unit's independence affects the structure of the management control system established by headquarters, our finding also contributes to the literature of management accounting. 
Our findings have implication for empirical research concerning the antecedents of spin-offs. Prior literature of this field has clarified various antecedents (Iturriaga \& Cruz 2008, Panela et al., 2019). This paper provided an attractive potential factor that should be examined.

\section{CONCLUSION}

We analyzed the choice of bargaining power from the perspective of the relationship between headquarters and business units. We find that the bargaining power choice by headquarters is negatively related to the importance of the operations of the business unit. This result has been confirmed by numerical examples. Our findings can be an explanation of why a business unit gradually acquires more independence from its parent company.

On the other hand, our study operationalizes bargaining power as a variable that is exclusively determined by headquarters. However, if we consider the possibility that an independent company chooses to become affiliated with other company through M\&A, our assumption provides only an incomplete assessment on the bargaining power choice between players. In future research, we can assume a situation in which all of the participants in the contract can influence the degree of bargaining power.

\section{ACKNOWLEDGEMENTS}

Okuda and Chujo would like to acknowledge the financial support which was awarded under the Grant-in-Aid for Scientific Research (C) No. 18K01915 and No. 17K04089, provided by the Japan Society for the Promotion of Science, respectively.

\section{REFERENCES}

Aoki, M. (1988). Information, incentives and bargaining in the Japanese economy: A microtheory of the Japanese economy. Cambridge: Cambridge University Press. 
Coase, R. H. (1937). The nature of the firm. Economica, 4(16), 386-405.

Grossman, S. J., \& Hart, O. D. (1986). The costs and benefits of ownership: A theory of vertical and lateral integration. Journal of Political Economy 94(4), 691-719.

Guo, H., Gu, S., \& Su, Y. (2018). Bargaining power choices with moral hazard in a supply chain. Discrete Dynamics in Nature and Society, 1-9.

Hart, O. D., \& Moore, J. (1990). Property rights and the nature of the firm. Journal of Political Economy, 98(6), 1119-1158.

Inderst, R. (2002). Contract design and bargaining power. Economics Letters 74(2), 171-176.

Ishida, J., \& Matsushima, N. (2009). An analysis of union behavior with endogenous bargaining power. Kokumin Keizai Zasshi, 200(2), 57-66 (in Japanese).

Iturriaga, F. L., \& Cruz, N. M. (2008). Antecedents of corporate spin-offs in Spain: A resource-based approach. Research Policy, 37(6-7), 10471056.

Levy, A. (1998). A theoretical analysis of trade union membership fees, bargaining power, wage rate and unemployment. Australian Economic Papers, 37(4), 404-413.

Penela, D., Estevão, J., \& Gregory, A. (2019). Accounting and financial antecedents of corporate spin-offs in the lodging industry. International Journal of Hospitality Management, 83, 151-158.

Sasaki, T., Yonezawa, Y., \& Azeez, A. A. (2008). Japanese corporate governance problem and economic efficiency: An empirical analysis of Japanese manufacturing firms. Oikonomika, 45(2), 41-64.

Williamson, O. (1985). The economic institutions of capitalism: Firms, markets, relational contracting. New York: The Free Press. 